\title{
MOLECULAR DYNAMIC SIMULATION OF ASIATIC ACID DERIVATIVES COMPLEX WITH INDUCIBLE NITRIC OXIDE SYNTHASE ENZYME AS AN ANTI-INFLAMMATORY
}

\author{
IDA MUSFIROH*, HANIFAHZIN KHATAMI, SANDRA MEGANTARA, MUCHTARIDI MUCHTARIDI
}

Department of Pharmaceutical Analysis and Medicinal Chemistry, Faculty of Pharmacy, Universitas Padjadjaran, Jatinangor, Sumedang, Indonesia

*Email: ida.musfiroh@unpad.ac.id

Received: 10 Sep 2020, Revised and Accepted: 08 Oct 2020

\section{ABSTRACT}

Objective: The aim of this study was to determine the stability interaction of asiatic acid derivatives (AA) complex with inducible nitric oxide synthase (iNOS) enzyme as an anti-inflammatory using Molecular Dynamic (MD) simulation.

Methods: The methods were consisting of validation of molecular docking, molecular docking to calculate binding affinity within the complex between the compounds and iNOS enzyme by using MMGBSA (Molecular Mechanics/Generalized Born Surface Area), and MD system preparation, MD production as well as MD analysis using AMBER18.

Results: The result of validation and molecular docking were AA5 has the most negative Gibbs energy that is -9.17 kcal/mol, which has better binding affinity than other derivatives than other derivatives. The molecular dynamics simulation of the modified structure of asiatic acid showed that binding energy value and RMSD of AA5, AA6 and AA9 have a lower value compared to arginine as a substrate of iNOS enzyme. Molecular Dynamics that have been occurred to the best three compounds chosen shown good result in terms of stability after 100 ns length simulation. And the lowest binding affinity has been achieved by a compound called AA5. Out of all ligands that have been simulated shown that their binding affinity was lower than AA5 that reached-44.6753 kcal/mol.

Conclusion: This studies conclude that AA5 considerably more potential as a selective inhibitor of iNOS enzyme as an anti-inflammatory.

Keywords: Molecular Dynamic, Asiatic acid derivatives, iNOS, Anti-inflammatory

(C) 2021 The Authors. Published by Innovare Academic Sciences Pvt Ltd. This is an open access article under the CCBYlicense (https://creativecommons.org/licenses/by/4.0/) DOI: https://dx.doi.org/10.22159/ijap.2021.v13s3.06 Journal homepage: https://innovareacademics.in/journals/index.php/ijap

\section{INTRODUCTION}

iNOS was one out of three kinds of enzyme NOS that has four pathways based on its structure that could be used as a target for an inhibitor; L-arginine-based inhibitor, Tetrahidrobiopterin $\left(\mathrm{H}_{4} \mathrm{~B}\right)$ based inhibitor, Heme, and Calmodulin based inhibitors [1]. These pathway has been used as leads for design a potent inhibitor. All kinds of NOS enzymes produce Nitric Oxide, a radical agent with specific roles, like iNOS; NO has been used to help the immune system, macrophage, kill and detect bacteria and virus that invaded the human body [2-4]. But, in consequence of killing these microorganisms, inflammation would occur in the specific site of our body. Also, the radical properties of NO can damage healthy cells that causing inflammation. Furthermore, a high concentration of NO in the human body can increase the risk of inflammation and oxidative stress for healthy cells [5].

Asiatic acid (AA) is one of a pentacyclic triterpenoid compounds derived from Centella asiatica, known as pegagan in Indonesia. AA has been known about its pharmacological activity for being an anti-inflammation agent that has been proved within vitro [6-8]. Also, in vivo study reported that the extract of Centella asiatica with a dose between $10-300 \mathrm{mg} / \mathrm{kg}$ towards one group of rats with edema in their feet showed a significant inflammation reduction $[7,9]$. The triterpenoid group includes AA has a role to reduce stress oxidation with its antioxidant activity because of its structure $[10,11]$. The structure of AA that has three groups of hydroxyl at $\mathrm{C}(2), \mathrm{C}(3), \mathrm{C}(23)$, olefin group at $\mathrm{C}(12)$ and one carboxylic acid group at $\mathrm{C}(28)$ play important roles for its ability to bind well to receptor binding site. In a previously study, the binding affinity of AA against iNOS was higher than COX-2 and as it reported that hydroxyl and carboxylic acid groups have a role as hydrogen bond acceptor and olefin group has a hydrophobic interaction with the receptor [12]. The derivatives compounds of AA5, AA6 and AA9 also have reported that their binding affinity against iNOS was preferable to become an iNOS inhibitor $[1,13$, 14]. But, Until now, the information about thus compounds stability against iNOS was not available yet. Whereas, that could become very essential information to consider the drug design and development of AA.

In silico studies in drug design and discovery were quite popular these days because of its advantages, cheaper research cost, and more workable when it comes to working out of a laboratory. Molecular Dynamic (MD) was one of in silico methods that enable the researcher to how molecular moving around and interact with each other dynamically [15] Also, have more features one of them was calculating binding energy, which is MMPB/GBSA, That could predict ligand affinity to its binding site [16]. This research was doing MD simulations to three best compounds that have been chosen before based on previous research conduct [1]. The purpose of the simulation was to acknowledge information about stability interaction between $\mathrm{AA}$ and the chosen derivatives as ligands against iNOS that being simulated in a controlled system that looks alike within the human body condition. The stability of AA compounds as ligands would be observed within 100 ns length of the simulation. While binding affinity of AA against iNOS would be calculate using MMGBSA method.

\section{MATERIALS AND METHODS}

\section{Materials}

Material was including of receptors that being used for molecular dynamics that were taken from RCSB.org protein database for the receptor. The ligands were consist of Asiatic acid derivatives that have different functional groups at C-2, C-3 and C23 positions [14]. The Functional group of AA5, AA6 and AA9 were $\mathrm{CH}_{3} \mathrm{COOH}$, $\mathrm{CH}_{3} \mathrm{COOH}$ and $\mathrm{CH}_{2} \mathrm{OAC}$; $\mathrm{C}=\mathrm{O}, \mathrm{C}=\mathrm{O}$, and $\mathrm{COOH} ; \mathrm{C}=\mathrm{O}, \mathrm{C}=\mathrm{O}, \mathrm{CH}_{2} \mathrm{OAC}$, respectively. The structures were created using ChemDraw 16 PerkinElmer Inc and showed at fig. 1. Arginine that was the substrate for iNOS itself also being used for negative control. While iNOS with PDB ID: 3E7G was chosen for simulation receptor. The methods contain of molecular docking and molecular dynamic that consist of system preparation; MD production and MD analysis using AMBER18. 


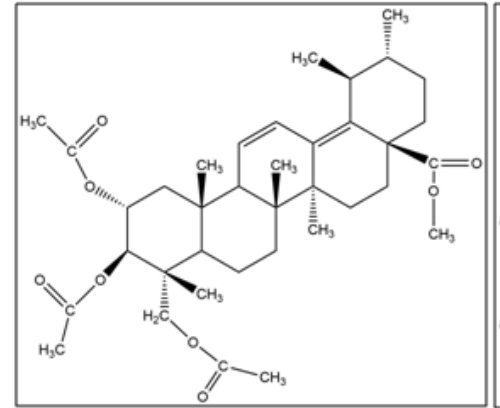

a.

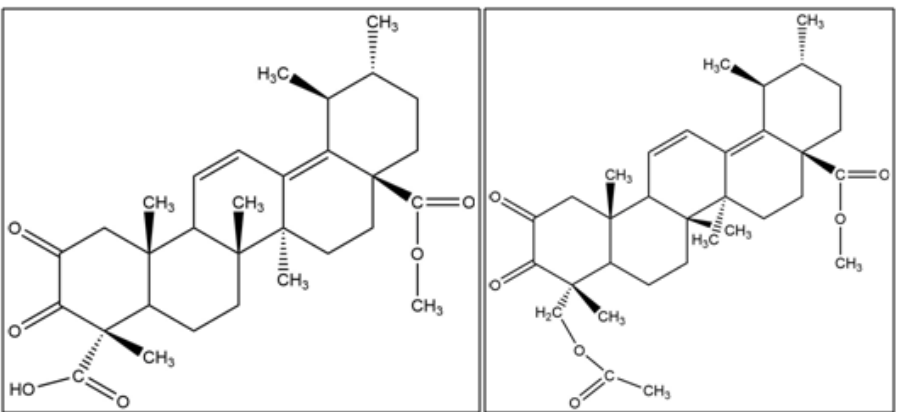

b. c.

Fig. 1: Structure of three chosen asiatic acid derivatives (a) AA5, (b) AA6, (c) AA9

\section{Validation of molecular docking}

Validation of molecular docking was performed between iNOS and Inhibitor AT2 as the natural ligand of iNOS (PDB: 3E7G) to ensure its exact coordinate and gridbox binding site that being used in Molecular Docking using AutoDockTools 4.2.

\section{Molecular docking}

Docked ligands-receptor into one unit was needed unless the MD simulation cannot showed the right information that we need for its complex properties. AA derivative compounds and iNOS were docked using AutoDockTools 4.2. Grid coordinate that used for iNOS (PDB ID: 3E7G) was 55.232, 21.838, 78.677 (x, y, z) with box size was 40:40:40.

\section{Molecular dynamic}

Desktop personal computer was being used with high specification (Processor: Intel i7-8550U, VGA: NVDIA GTX 970, Memory: Crosair DDR3 8GB) to overcome the needed of the hard task and long-time that computer would been done during the simulation. AMBER18 was a program that was used for the MD simulation. There was 3 steps for molecular dynamic; system preparation; MD production and MD analysis. A proper system with stability and controlled parameters were needed to be set before the simulation or MD production being done.

System preparation which has two-step; minimization and equilibration were also done using AMBER18 with specific "pmemd" command. Heating up the MD system also being done with AMBER 18 , which in this research were heat up until approximately $310 \mathrm{~K}$ and equilibration step were ran for at least $1.5 \mathrm{~ns}$. Equilibration was monitored by determining the stability of temperature, energy and density of the system as well as the RMSD.

The production time of MD was 100 ns length of time, to make sure the complex stability within the system which was set to look alike in the human body (Temperature approximately $310 \mathrm{~K}$, Pressure 1 $\mathrm{atm}$, and Volume $1 \mathrm{~g} / \mathrm{ml}$ ). Data were collected every $10 \mathrm{~ns}$ during the MD run. Visualization of protein-ligand complexes and MD tracectory analysis were carried out by VMD software package. Binding affinity of the complex would be calculated with MMGBSA method, calculated total of polar surface area energy, and solvated energy within the complex.

\section{RESULTS AND DISCUSSION}

Validation that has been done before between iNOS (PDB 3E7G) and inhibitor AT2 as its ligand showed that there are 3 spesific amino acid residues Glu377, Ala351, Tyr373, Tyr347. There was other research that reported specific amino acid residues, which are Glu377, Arg266 and Gln263 [17]. Also, resulting a RMSD which value is $0.974 \AA$, a preferable value because it was less than $2 \AA$ that being recommended for a good value of RMSD $[18,19]$. Detail result of the validation can be seen at table 1 . and the docking visualization showed at fig. 2.

Table 1: Result of molecular docking validation iNOS against AT2

\begin{tabular}{|c|c|c|c|c|c|c|}
\hline Enzyme & Grid/(Å) ${ }^{3}$ & Coordinate $(x$, & $\Delta \mathrm{G}(\mathrm{kcal} / \mathrm{mol})$ & $\mathrm{Ki} /(\boldsymbol{\mu M})$ & RMSD (A) & Amino acid residue \\
\hline iNOS & 40: $40: 60$ & $\begin{array}{l}\mathbf{y}, \mathbf{z}) \\
55.23221 .838 \\
78.677\end{array}$ & -5.03 & 210.83 & 0.974 & $\begin{array}{l}\text { H-bond } \\
\text { Tyr373;Tyr347;Glu377;Ala351. }\end{array}$ \\
\hline
\end{tabular}

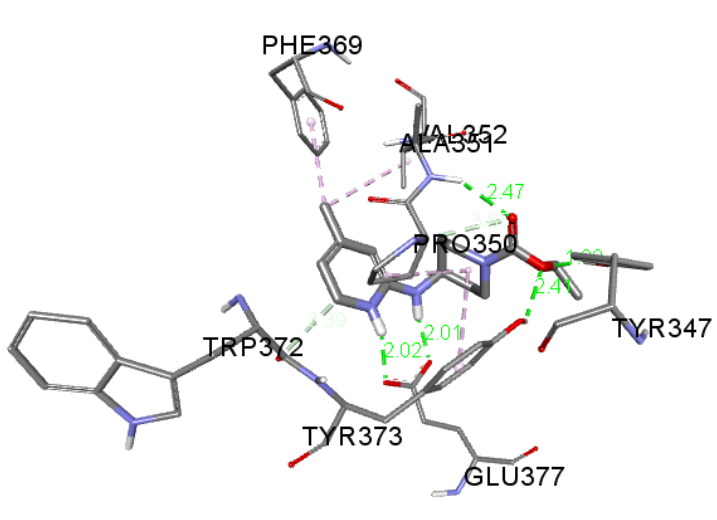

a

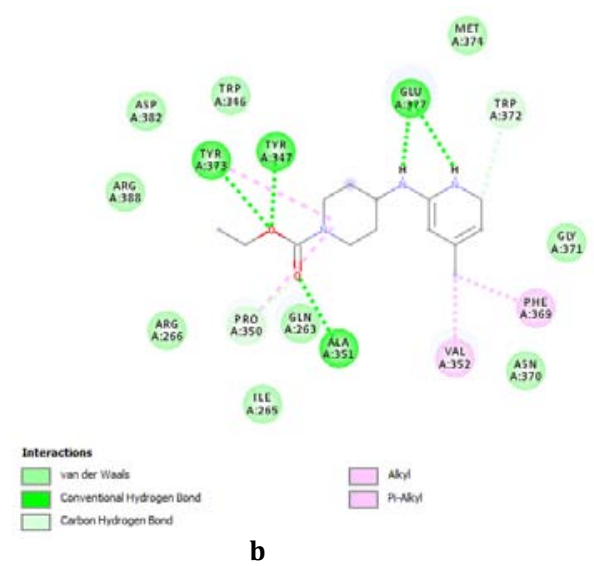

Fig. 2: Visualisation of complex AT2 and iNOS (PDB: 3E7G). (a) 3D Visualisation that showed hydrogen bond and Hydrophobic interaction. (b) 2D Visualisation that showed hydrogen bond, Van der waals and Hydrophobic interaction. 
After the validation of the binding site has been done with the preferable RMSD, the research was continued with another molecular docking trial. This time, the AA derivatives would be prepared to be docked with the parameter that was previously established. The docked were ran 100 times for one docking, and each compound would be undergo three times of docking. The result of the docking was showed in the table 2. Based on the result, the derivative compound named AA5 has seem to be the best result than other derivatives. The parameters that refer to AA5 stated before was considered the result of gibbs energy, constant inhibition, the number of docked and also the specific amino acid residues that binded with the ligand formed a hydrogen bond. AA5 has the most negative Gibbs energy that is $-9.17 \mathrm{kcal} / \mathrm{mol}$, which is the better binding affinity than other derivatives [20]. Also, AA5 has primacy of its constant inhibition value, which is $188.86 \mathrm{nM}$, where that is the most lower value than the other compounds. Furthermore, the highest value number of docked was achieved by AA5, which was done 84 out 100 times of dock.

Table 2: Molecular docking result of asiatic acid derivatives against iNOS (PDB 3E7G)

\begin{tabular}{|c|c|c|c|c|c|}
\hline Compound & Grid $(\AA)^{3}$ & $\Delta \mathrm{G}(\mathrm{kcal} / \mathrm{mol})$ & $\mathbf{K i}$ & $\begin{array}{l}\text { Number of docked } \\
\text { (100 run) }\end{array}$ & $\begin{array}{l}\text { Amino acid residues } \\
\text { H-bond }\end{array}$ \\
\hline AA5 & $40: 40: 60$ & -9.17 & $188.86 \mathrm{nM}$ & $84 / 100$ & Arg381; Trp372 \\
\hline AA6 & $40: 40: 60$ & -8.31 & $807.11 \mathrm{nM}$ & $65 / 100$ & Val352 \\
\hline AA9 & 40: $40: 60$ & -7.43 & $3.56 \mu \mathrm{M}$ & $56 / 100$ & Gly371; Trp372 \\
\hline
\end{tabular}

Before complexes were undergo molecular dynamic simulation, they were docked using AutoDockTools. So the ligands and iNOS as its target could be united as a complex. Docking simulations that have been done also gave prediction about binding affinity, stability, and interaction between ligand and receptor. In case, AA5 which has the lowest binding energy that is $-10.16 \mathrm{kcal} / \mathrm{mol}$ than other two chosen derivatives AA6 $(-9.90 \mathrm{kcal} / \mathrm{mol})$ and AA9 $(-9.17 \mathrm{kcal} / \mathrm{mol})$ that have lower binding energy after being docked before, and this result in line with previous research [14]. With the docking result of the AA derivatives binding energy, we can predict their binding affinity against iNOS when they went to MD simulation. The lower binding energy of ligand toward a receptor that would means the ligand would easier binded to its receptor and vice versa [20].

Stability prediction could be done by observing the number of docked a ligand against receptors. Number of docked means total of a specific conformation that formed and being docked towards its receptor. The higher number of docked at a specific conformation would be better because of that conformation has high acceptable probability and stability since it's continuously formed and docked against its target receptors [21]. Using molecular dynamic, drug design and discovery would become easier and getting more information about the body interferes to the drug candidate. There more advantages of MD that enabled for observed the interaction of ligand-receptor target freely and dynamically so that the prediction of drug properties in the human body could be more precise [22].

Molecular dynamic simulation that divided into three-step which is preparation, production, and analysis. The preparation step was a step for complex ligands-receptors to equilibrating its system that has been set to the human body at least more than $1.5 \mathrm{~ns}$ or $1500 \mathrm{ps}$. To ensure the system has been perfectly equilibrated. Fig. 3. Below showed the graph of the parameter that being equilibrated which is volume, density, temperature and pressure. Each parameter need to be constant as long as the equilibration steps were ran, while for the beginning steps the parameter would be adjusting itself to achieve the preferable value that is set before. Temperature for the system has been set for $310 \mathrm{~K}$, to the controlled system to be look-alike in the human body. So as the other parameter, density was set around $1 \mathrm{~g} / \mathrm{ml}$, and volume was being set to reach and keeping that constant value while the other system was being adjusted.

The time length of two first step was optimized before, especially for preparation step that occur in 1.5 ns were optimized for getting the preferable system. Production step itself was ran within 100 ns that being separated into 10 parts, so it would minimized error and other non-desired things. Some MD researchs were gave recommend time length for production step which was based on how much the residues of amino acid in a receptor, more residues were recommended to have a more longer time of simulation which could be done up to $100 \mu$ s [23]. There, it was also reported that simulation duration within $100 \mathrm{~ns}$ comes out a proper result $[19,24,25]$. All of the ligands that ran with iNOS showed good stability for binding to iNOS binding site within $100 \mathrm{~ns}$ except for the L-arginine that was substrate for iNOS were chosen as control negative that also simulated to compare its activity against other inhibitors, L-arginine could not stay put in iNOS binding site for $100 \mathrm{~ns}$. Its bond was cut off after simulation ran for $40 \mathrm{~ns}$, and then leaves the binding site. These results showed that the asiatic acid derivatives can compete with the substrate to occupy the active site of the iNOS enzyme, which can synthesize NO as inflammatory cytokines.

Meanwhile, all of the chosen AA derivatives have been observed for each of 100 ns and showed that they were not move out with iNOS binding site. During molecular dynamics simulations, especially in system containing AA5 as ligand. Several specific amino acid residues have been found that affect the quality of the bonds possessed by complex ligand-receptors in this system that illustrated in fig. 4. The residues are hydrogen-bonded with AA5, which is a bond that is desirable to exist in a complex of drugtarget site. Because hydrogen bond allow to increase bond stability and decrease the bond energy of a complex. Specific amino acid residues that have these bonds are Gly289 and Met292. It is assumed that these two residues become important amino acid residues that influence the binding activity of AA5 to iNOS (PDB: 3E7G).

After the preparation step was the MD simulation phase or production step. Simulation of Molecular Dynamic has been done for 100 ns. The analysis of stability each complex of three chosen Asiatic acid derivatives and iNOS were done by observed its ligand ability to stay binded as long as possible. After 100 ns simulation, output file of MD opened by an application named Visual Molecular Dynamic (VMD) that made its file became likely visible and easier to observe. Result showed at, that all of the chosen compounds derivative have good stability. Because of their bond with receptor were kept in place. In other hand, L-arginine that used to be substrat for iNOS showed that its bond was cut off with iNOS before the simulation reach $40 \mathrm{~ns}$. So that, L-arginine have less stability than the three best Asiatic acid derivatives chosen.

Root Mean Square Deviation (RMSD) also being observed, which showed the information of reproducibility each system of molecular dynamics conducted. Detail information about differences of system were showed in table 3 and illustrated in fig. 5 for all trajectory of MD simulation. The detail differences about RMSD for $100 \mathrm{~ns}$ long simulation can be seen at this figure, that AA5 showing the respectively lower RMSD than other derivatives. It would means that AA5 have suitable structure towards iNOS binding site that be able to create good reproducibility when other simulation conduct. Also, for the information of amino acid residues that being fluctuated because of AA derivatives binded onto its receptor, it could be seen at fig. 6 . That showed the fluctuation of certain residues of iNOS (PDB: 3E7G). 


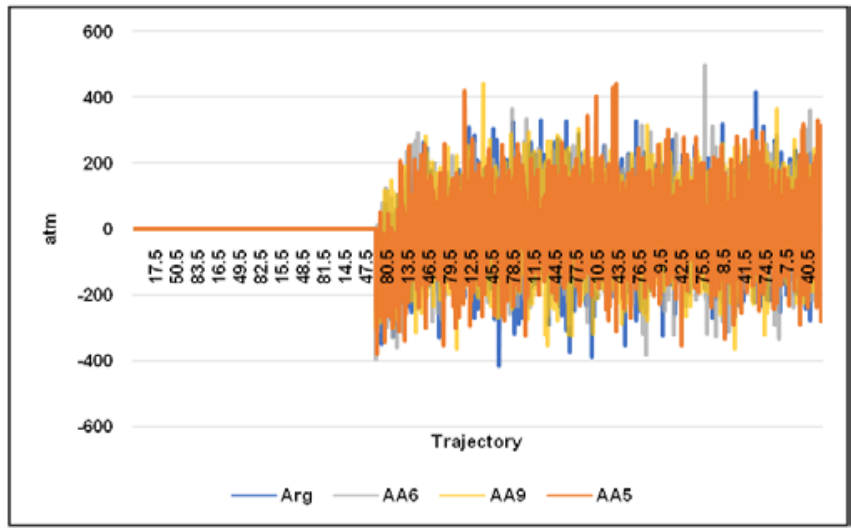

a

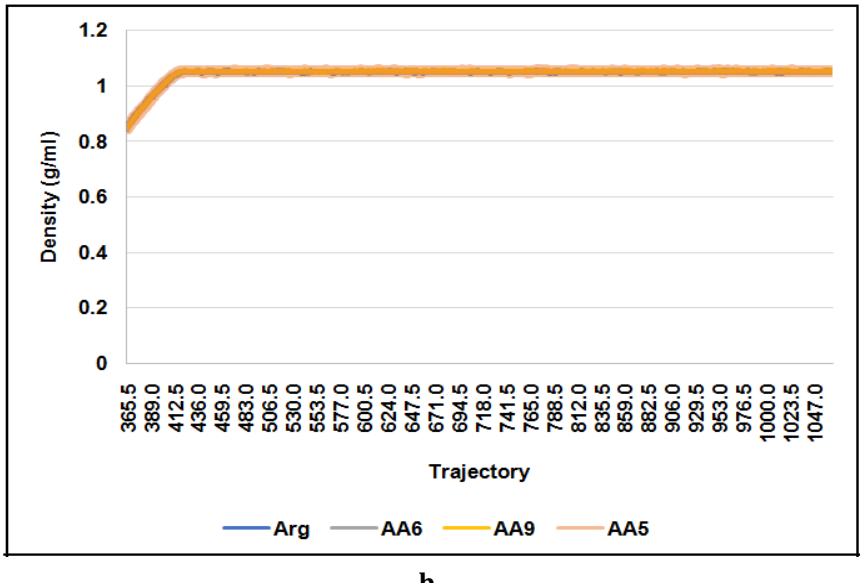

b

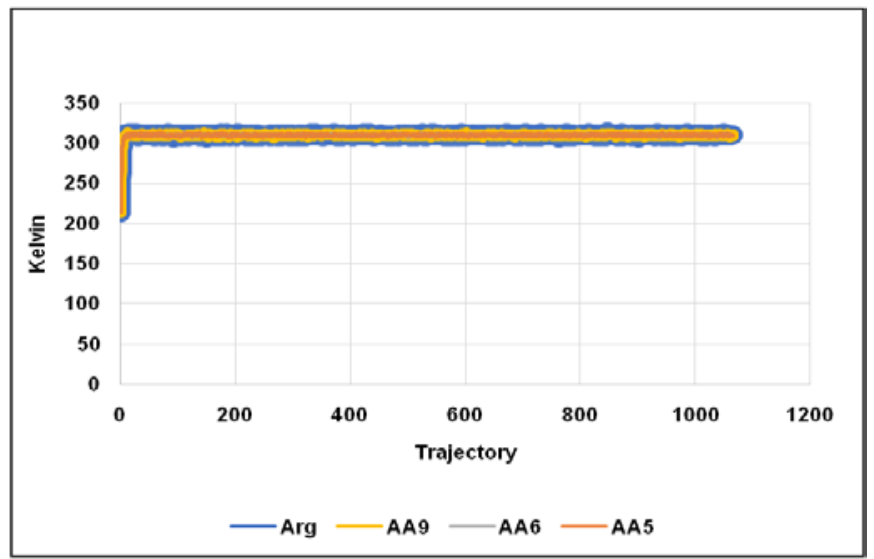

c

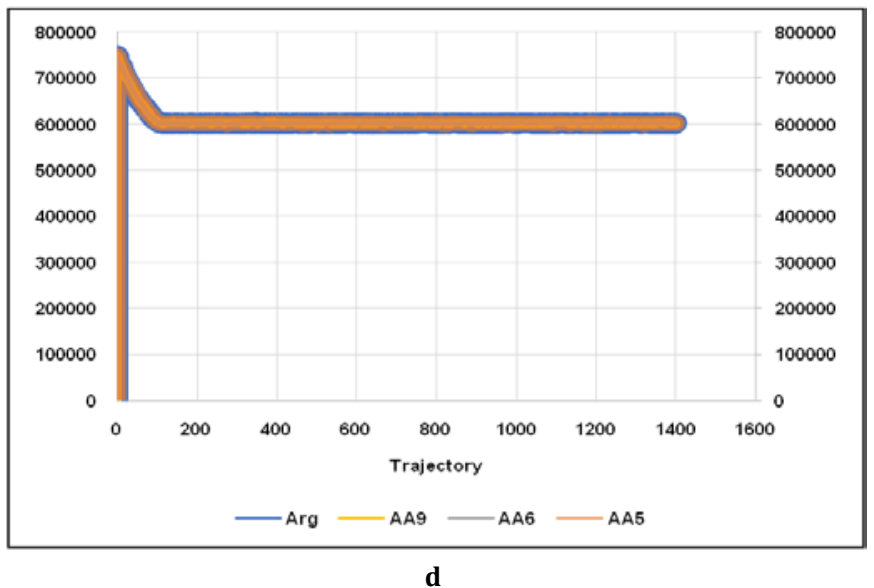

Fig. 3: Result of preparation and equilibration step: a. Pressure, b. Density, c. Temperature, d. Volume 


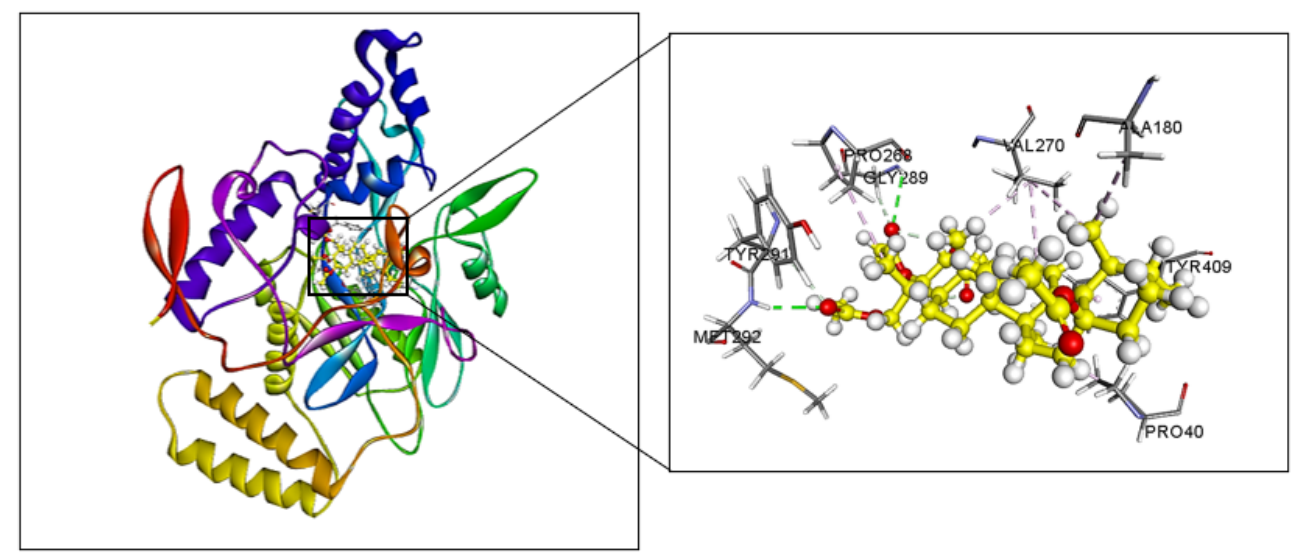

Fig. 4: Interaction of AA5 and iNOS (PDB: 3E7G) after being simulated for 100ns

Table 3: RMSD result of the chosen Asiatic acid derivatives MD system

\begin{tabular}{lllll}
\hline Trajectory & RMSD value $(\AA)$ & & \\
\cline { 2 - 4 } & AA5 & AA6 & AA9 & Arginine \\
\hline 1000 & 0.5861 & 0.7046 & 1.0949 & 1.781 \\
\hline
\end{tabular}

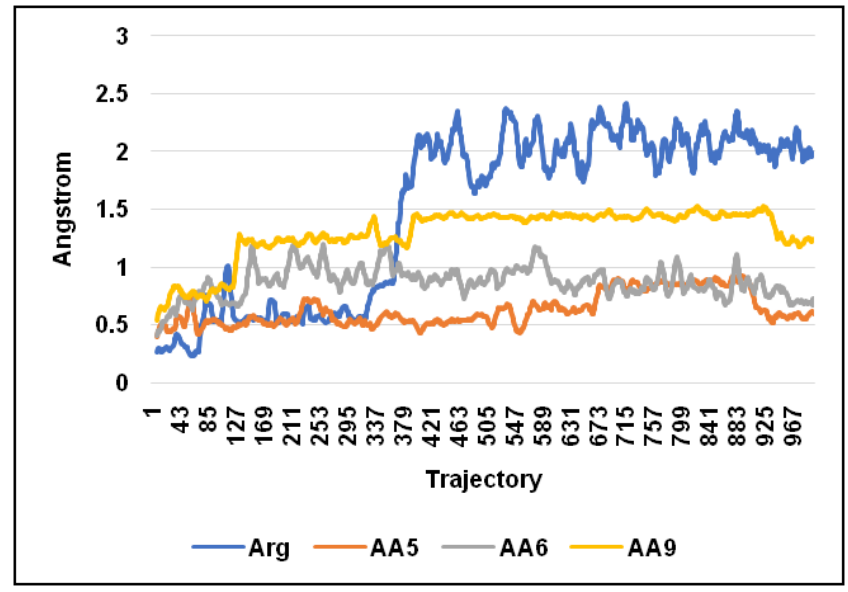

Fig. 5: RMSD of each system after 100ns MD simulation

The data in fig. 5 represents the RMSD of each arginine system as control ligands, AA5, AA6, and AA9 as experiment ligands. In that data, it is known that there was an increase in RMSD for AA6 and AA9 after the trajectory reached 115 and after reaching the 305 trajectories. The increase of RMSD also occurred at Arginine. As for AA5, it looks more stable despite an increase in RMSD after the trajectory reached 647, which returned to stable afterward. Possible suspicion of an increase in RMSD that occurs in simulations is because of some bonds that been released between the ligand and the receptor at certain times, the ligand that is released will try to find other the binding site of the receptor that is suitable for itself so that both achieve stability. if stability cannot be achieved, then the ligand will detach itself. This was concluded after seeing the movement of Arginine, which was surprisingly detached from the boundary of the iNOS (PDB: 3E7G) slowly after the simulation trajectory reached 305 and was completely released after the 495500 trajectory. By observing the result, AA5 is the compound that is predicted to have the best bond stability because the results of visualization using VMD (Visual Molecular Dynamic) show the strong bond between the ligand (AA5) and receptor (iNOS). Beside considering the RMSD the stability of the bond between the ligands and receptors could be determined by calculating the non-bonded energy [26], and the LIE (Linear Interaction Energy) [27, 28] of each system. LIE allows researchers to analyze changes in the energy of interactions between ligands and proteins on average during the simulation process [29].

Binding affinity for each ligands has been calculated using MMGBSA method that was included in AMBER18 features. For the detail result of MMGBSA calculation can be seen in table 4. Based on the result, the lowest energy of binding energy was achieved by AA5 with $-44,6753 \mathrm{kcal} / \mathrm{mol}$. With that, AA5 could be predicted have the most preferable binding affinity, which is have directly proportional related to energy binding.

Calculation of binding energy to predict the binding affinity of three chosen AA derivatives against iNOS was used MMGBSA as method. Actually, there is another method to calculate energy binding within the complex which is MMPBSA (Molecular Mechanics PoissonBoltzmann Surface Area). Some reports told that MMGBSA method was recommended to be used for calculating binding energy in drug design and discovery because of its higher accuracy nevertheless its precision was lower to MMGBSA method [30-32]. Calculation result showed that AA5 has the lowest binding energy, which value is $-44.6753 \mathrm{kcal} / \mathrm{mol}$. Van der waals was the interaction that gave the most role for AA5 binding energy. The amount of Van der waals interactions were take biggest role for its MMGBSA calculation. Visualisation of each system with Biovia Discovery was 
showed that system of AA5 have more Van der waals interaction than other system. So as, the result that could be seen at table 4 , its make even stronger prove for AA5 being recommended to be the best inhibitor against iNOS out of other chosen AA derivatives.

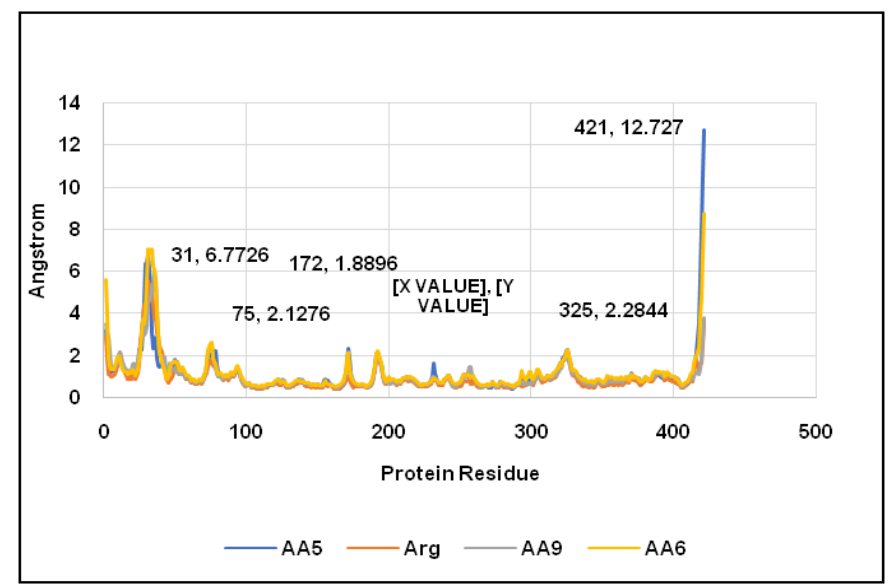

Fig. 6: Fluctuation of each system after 100ns MD simulation, there are some peaks that are referring specific residues that being impacted of AA derivatives

Table 4: MMGBSA calculation result of three chosen asiatic acid derivatives

\begin{tabular}{llll}
\hline Energy component (kcal/mol) & Compound & & AA6 \\
\cline { 2 - 4 } & AA5 & -0.0000 & 0.0000 \\
\hline BOND & 0.0000 & 0.0000 & -0.0000 \\
ANGLE & -0.0000 & 0.0000 & 0.0000 \\
DIHED & -0.0000 & -50.5794 & -47.6234 \\
VDWAALS & -61.0854 & -1.8898 & -14.1987 \\
EEL & -15.6947 & 20.5868 & 31.7559 \\
EGB & 39.4884 & -5.9329 & -5.9227 \\
ESURF & -7.3836 & -52.4692 & -61.8221 \\
DELTA G Gas & -76.7801 & 14.6539 & 25.8333 \\
DELTA G Solv & 32.1048 & -37.8152 & -35.9888 \\
DELTA TOTAL & -44.6753 & & \\
\hline
\end{tabular}

*EEL: Electrostatic energy, EGB: Energy of Generalized Born; ESURF: Energy of Surface; VDWAALS: Van der Waals

The time length of two first step were optimized before, especially for preparation step that occur in 1.5 ns were optimized for getting the preferable system. Production step itself was run within 100ns that being separated into 10 parts, so it would minimized error and other non-desired thing. Some MD researchs were gave recommend time length for production step which were based on how much the residues of amino acid in a receptor, more residues were recommended to have a more longer time of simulation which could be done up to $100 \mu$ s [23]. There, was also reported that simulation duration within $100 \mathrm{~ns}$ comes out a proper result [19, 24, 25]. All of the ligands that ran with iNOS showed good stability for binding to iNOS binding site within $100 \mathrm{~ns}$ except for the L-arginine that was substrate for iNOS were chosen as control negative that also simulated to compare its activity against other inhibitors, L-arginine could not stay put in iNOS binding site for $100 \mathrm{~ns}$. Its bond was cut off after simulation ran for $40 \mathrm{~ns}$, and then leaves the binding site. These results showed that the asiatic acid derivatives can compete with the substrate to occupy the active site of the iNOS enzyme, which can synthesize NO as inflammatory cytokines.

Furthermore, the molecular docking result that showed at table 2 gave an inline information with the MD simulation for the interaction of AA derivatives compounds against iNOS enzyme. After 100 times of dock AA5, AA6 and AA9 have got more lower binding energy than arginine. While AA5 could being docked perfectly with target site of iNOS for 84 times out 100 run, as well as has the most stable structure after $100 \mathrm{~ns}$ and can stay more longer on iNOS binding site during molecular dynamics simulations. Based on this study showed that AA5, AA6 and AA9 were predicted as anti- inflammatory and AA5 that more selectively to inhibit the activity of iNOS enzyme.

\section{CONCLUSION}

The molecular dynamics simulation of the modified structure of asiatic acid showed that binding energy value and RMSD of AA5, AA6 and AA9 have a lower value compared to arginine as a substrate of iNOS enzyme. However, AA5 has RMSF graph comes up with high fluctuations in spesific iNOS amino residues. AA5 considerably more potential as a selective inhibitor of iNOS enzyme as an anti-inflammatory. In vitro and in vivo studies need to be done to ensure its activity.

\section{ACKNOWLEDGEMENT}

We would like to thank to The Ministry of Education and Culture Republic Indonesia, which has supported this research through PDUPT grant at 2020. We also thank to the computational laboratory of Department of Chemistry Faculty of Mathematics and Natural Science for providing the use of the Software.

\section{FUNDING}

Nil

\section{AUTHORS CONTRIBUTIONS}

All the authors have contributed equally.

\section{CONFLICTS OF INTERESTS}

Declared none 


\section{REFERENCES}

1. Kartasasmita RE, Musfiroh I, Muhtadi A, Ibrahim S. Binding affinity of asiatic acid derivatives design against inducible nitric oxide synthase and ADMET prediction. J Appl Pharm Sci 2014;4:75-80.

2. Vítecek J, Lojek A, Valacchi G, Kubala L. Arginine-based inhibitors of nitric oxide synthase: therapeutic potential and challenges. Mediators Inflamm 2012. https://doi.org/ $10.1155 / 2012 / 318087$.

3. Hamalainen M. Inducible nitric oxide synthase as a target of treatment modalities; 2008.

4. Förstermann U, Sessa WC. Nitric oxide synthases: regulation and function. Eur Heart J 2012;33:829-37.

5. Bogdan C. Nitric oxide synthase in innate and adaptive immunity: an update. Trends Immunol 2015;36:161-78.

6. Nakazawa H, Chang K, Shinozaki S. iNOS as a driver of inflammation and apoptosis in mouse skeletal muscle after burn injury: possible involvement of sirt1 S-nitrosylationmediated acetylation of p65 NFeKB and p53. PLoS One 2017;12:1-18.

7. Lv J, Sharma A, Zhang T, Wu Y, Ding X. Pharmacological review on asiatic acid and its derivatives: a potential compound. SLAS Technol 2018;23:111-27.

8. Huang SS, Chiu CS, Chen HJ. Antinociceptive activities and the mechanisms of anti-inflammation of asiatic acid in mice. Evidence-Based Complement Altern Med 2011. DOI:10.1155/2011/895857.

9. Marbun EMA, Restuati M. Pengaruh ektrak etanol daun buasbuas (premna pubescens blume) sebagai antiinflamasi pada edema kaki tikus putih (Rattus novergicus). J Biosains 2015;1:107-22.

10. Gohil KJ, Patel JA, Gajjar AK. Pharmacological review on centella asiatica: a potential herbal cure-all. Indian J Pharm Sci 2010;72:546.

11. Hashim P, Sidek H, Helan MHM, Sabery A, Palanisamy UD, Ilham M. Triterpene composition and bioactivities of centella asiatica. Molecules 2011;16:1310-22.

12. Musfiroh I, Nursamsiar, Muhtadi A, Kartasasmita RE, Tjahjono DH, Slamet Ibrahim S. In silico study of asiatic acid interaction with inducible nitric oxide synthase (iNOS) and cyclooxygenase-2 (COX-2). Int J Pharm Pharm Sci 2013;5(Suppl 1):204-7.

13. Musfiroh I, Sri Rizky W, Winasih, Muhtadi A, Kartasasmita RE, Ibrahim S. QSAR study of asiatic acid and its derivatives as potential inducible nitric oxide synthase (iNOS) inhibitors. Int J Chem Sci 2015;13:1459-73.

14. Musfiroh I, Septiandi I, Megantara S, Tjitraresmi A, Muchtaridi. Interaction analysis of asiatic acid and its derivatives to three isozyme of nitric oxide synthase (NOS) using molecular docking. Res J Chem Environ 2019;23:87-93.

15. Meng Y, Sabri Dashti D, Roitberg AE. Computing alchemical free energy differences with hamiltonian replica exchange molecular dynamics (H-REMD) simulations. J Chem Theory Comput 2011;7:2721-7.

16. If all I, Hasanuddin A, Rahim A, Kadir S. Modifikasi pati secara asetilasi terhadap gugus fungsi asetil dan kristanilitas pati ubi banggai asetat. Rekayasa 2019;12:135-40.

17. Poulos TL, Li H. Nitric oxide synthase and structure-based inhibitor design. Nitric Oxide Biol Chem 2017;63:68-77.

18. Azam F, Abugrain IM, Sanalla MH, Elnaas RF, Rajab I. In silico investigation of the structural requirements for the AMPA receptor antagonism by quinoxaline derivatives. Bio information 2013;9:864-9.

19. Roy J, Laughton CA. Long-time-scale molecular-dynamics simulations of the major urinary protein provide atomistic interpretations of the unusual thermodynamics of ligand binding. Biophys J 2010;99:218-26.

20. Du X, Li Y, Xia YL. Insights into protein-ligand interactions: mechanisms, models, and methods. Int J Mol Sci 2016;17:1-34.

21. Chang MW, Ayeni C, Breuer S, Torbett BE. Virtual screening for HIV protease inhibitors: a comparison of AutoDock 4 and vina. PLoS One 2010;5:e11955.

22. Hospital A, Goñi JR, Orozco M, Gelpi JL. Molecular dynamics simulations: advances and applications. Adv Appl Bioinforma Chem 2015;8:37-47.

23. Bowman GR. Accurately modeling nanosecond protein dynamics requires at least microseconds of simulation. J Comput Chem 2016;37:558-66.

24. Abdulazeez S. Molecular simulation studies on B-cell lymphoma/leukaemia 11A (BCL11A). Am J Transl Res 2019;11:3689-97.

25. Sargsyan K, Grauffel C, Lim C. How molecular size impacts RMSD applications in molecular dynamics simulations. J Chem Theory Comput 2017;13:1518-24.

26. Maulana FA, Ambarsari L, Wahyudi ST. Homology modeling and structural dynamics of the glucose oxidase. Indones J Chem 2020;20:43-53.

27. Barrientos A, Concha F. Phenomenological model of classification in conventional hydrocylones. Comminution 1990;819:287-305.

28. Hansson T, Marelius J, Aqvist J. Ligand binding affinity prediction by linear interaction energy methods. J Comput Aided Mol Des 1998;12:27-35.

29. Wickstrom L, Gallicchio E, Levy RM. The linear interaction energy method for the prediction of protein stability changes upon mutation. Proteins Struct Funct Bioinforma 2012;80:111-25.

30. Genheden S, Ryde U. The MM/PBSA and MM/GBSA methods to estimate ligand-binding affinities. Expert Opin Drug Discovery 2015;10:449-61.

31. Virtanen SI, Niinivehmas SP, Pentikäinen OT. Case-specific performance of MM-PBSA, MM-GBSA, and SIE in virtual screening. J Mol Graph Model 2015;62:303-18.

32. Sun H, Duan L, Chen F. Assessing the performance of MM/PBSA and MM/GBSA methods. 7. Entropy effects on the performance of end-point binding free energy calculation approaches. Phys Chem Chem Phys 2018;20:14450-60. 